\title{
Deep Disagreement, Rational Resolutions, and Critical Thinking
}

\section{RichaRd FELDMAN}

\author{
University of Rochester
}

\begin{abstract}
According to Robert Fogelin, deep disagreements are disagreements about fundamental principles. He argues that deep disagreements cannot be rationally resolved. In this paper I argue against this thesis. A key part of the response depends upon the claim that disagreements can be rationally resolved not only by one participant rationally coming around to the other's point of view, but also by both of them rationally suspending judgment about the disputed proposition. I also claim that suspension of judgment may be the rational response in the examples Fogelin characterizes as deep disagreements. I deny that this result has any troubling implications for critical thinking.
\end{abstract}

Résumé: Selon Robert Fogelin, des désaccords profonds sont des désaccords sur des principes fondamentaux. J'argumente contre sa thèse qu'on ne peut pas résoudre des désaccords profonds. Un aspect central de ma critique repose sur l'idée qu'on peut rationnellement résoudre des désaccords non seulement lorsqu'un des participants au désaccord vient à adopter rationnellement l'avis de l'autre, mais aussi lorsque les deux suspendent rationnellement leur jugement sur le point en litige. J'avance aussi que la suspension de jugement peut être la réponse rationnelle aux exemples de désaccord profond identifiés par Fogelin. Ce résultat n'a aucune implication troublante pour la pensée critique.

Keywords: : Fogelin, deep disagreements, rational resolution, suspension of judgment

Robert Fogelin (1985) defends a pessimistic thesis about the possibility of the rational resolution of disagreements of a particular kind. His thesis is that "deep disagreements cannot be resolved through the use of argument, for they undercut the conditions essential to arguing" (p. 5). He also puts his thesis this way, "if deep disagreements can arise, what rational procedures can be used for their resolution? The drift of this discussion leads to the answer NONE" (p. 6). He concludes his essay by saying that we should acknowledge that these disagreements "by their nature, are not subject to rational resolution" (p. 7). He rightly notes that this is a distressing result for the critical thinking movement, since its advocates "give the impression that they possess the resources to resolve such disagreements" (p. 6).

In this paper I will examine Fogelin's defense of this thesis. I will argue for a less pessimistic conclusion. 


\section{Fogelin's Position}

In this section I will try to flesh out Fogelin's thesis and the key claims he uses to support it. I will formulate Fogelin's thesis as follows:

F. Deep disagreements cannot be rationally resolved.

I note that (F) contains no explicit quantifier and leaves unclear whether the intended thesis is that all deep disagreements cannot be rationally resolved, or that some of them cannot be rationally resolved, or some particular kinds of deep disagreements cannot be rationally resolved. For present purposes, I will take the claim to be that no deep disagreements can be rationally resolved.

Understanding $(\mathrm{F})$ obviously requires some grasp of what a deep disagreement is. The clearest statement Fogelin provides of what constitutes a deep disagreement is in his remark that "We get a deep disagreement when the argument is generated by a clash of framework propositions" (p. 5). He also describes them as disagreements involving "underlying principles" (p.5). He gives as examples moral disagreements about abortion and about affirmative action. He says that the former rests on a disagreement over whether immortal souls enter newly fertilized eggs and the latter turns on differences over whether groups, in addition to individuals, have moral status. Presumably, then, he thinks that propositions such as "Immortal souls enter newly fertilized eggs" and "Groups have moral status" are framework propositions.

Fogelin goes on to say that in disputes over framework propositions, we will find not simply specific additional supporting propositions, but instead "a whole system of mutually supporting propositions (and paradigms, models, styles of acting and thinking) that constitute, if I may use the phrase, a form of life" (p. 6). In disagreements of this sort, he thinks, our normal argumentative devices do not work, and "they undercut the conditions essential to arguing" (p. 5).

Fogelin's argument is thus reasonably straightforward: Deep disagreements are disagreements resulting from a clash of framework propositions. But framework propositions depend for their support not on other individual propositions but rather "on systems of mutually supporting propositions (and paradigms, models and styles of acting and thinking.)" Differences over these matters are not amenable to rational resolution. His conclusion, $(\mathbf{F})$, follows.

\section{Rational Resolution}

As Fogelin notes, disagreements need not be deep to be unresolvable. One person may be "dense or pig-headed" and so refuse to concede a point that has been effectively established. Thus, from the fact two people may have temperaments that prevent them from resolving a disagreement, it does not follow that their disagreement is incapable of rational resolution. In other words, disagreements can be rationally resolvable, even if the parties to the disagreement are not rational and would not resolve their disagreement by following the methods of rational argumentation. In such cases, we might say that there is a rational resolution available, even if the people involved 
will not take advantage of it. Thus, a disagreement is rationally resolvable provided a rational resolution is available. But what makes an available resolution a rational resolution? And under what circumstances is such a resolution available?

One might think that a rational resolution of a disagreement is a resolution resulting from the use of the methods and techniques of rational thought. These are the methods typically developed in critical thinking courses. For present purposes we need not worry about exactly what they include. It is enough to note that they include the use of arguments and the logical analysis of evidence. They do not include the use of threats, force, intimidation, bribes, stirring musical themes, and the host of things many of us warn our students to look out for. Roughly, they do not include much of what we find in advertising and politics. Rational techniques include the frequently dry methods found in good academic writing and discussion.

Consider next what it is for a rational resolution to be available. One suggestion is that a particular way of resolving a disagreement is available if there are actions the participants to the disagreement could undertake that would lead them to that resolution. Applying this idea of availability to the account of rational resolution just stated yields something like this:

$\mathrm{RR} 1$. There is a rational resolution of a disagreement available when there is some way of presenting arguments and evidence such that, if the participants in the disagreement were to pursue it, they would resolve their disagreement.

According to (RR1), whether a disagreement is subject to rational resolution depends in part upon the psychologies and behavioral tendencies of the parties to the disagreement. (RR1) also implies that whether there is a rational resolution available depends in part upon the whether the use of a particular set of methods would lead to its resolution. I believe that both of these features of (RR1) make it unsuitable for present purposes. As we have already seen, just because two individuals have psychological make-ups that prevent their disagreement from being resolved, it does not follow that no rational resolution of their disagreement is available. Yet (RR1) does not respect this fact. It makes the availability of a rational resolution dependent upon the participants' ability to achieve resolution by engaging in a certain process. This is surely not what Fogelin intended. Where pig-headedness is the cause of the lack of resolution, the fault lies in the people. A rational resolution may be available, but the pig-headed people are not capable of taking advantage of it. Thus, they might consider arguments, evaluate evidence, and follow the methods of critical thinking, yet not reach agreement.

There is a second reason to reject (RR1) as our account of the availability of a rational resolution. Suppose that Fogelin is right and disagreements about framework principles are not susceptible to rational resolution. It is unlikely that (RR1) will help to support this point. The reason for this stems from its lack of a normative or evaluative element. Fogelin, and much of the related literature, emphasizes cases in which people stick to their guns in disputes and fail to reach agreement. However, 
there are also cases - real as well as possible--in which people do reach agreement as a result of arguments and evidence when they ought not. That is, some people give in too easily, they concede points they ought not concede, they are too readily persuaded by the arguments and evidence presented to them. In such cases, their disagreement may reach a resolution in that they come to agreement. Moreover, the resolution of the disagreement may involve only the use of arguments and the consideration of evidence. However, I am confident that Fogelin does not want to count this as sufficient for the resolution being a rational one. If it did count, then, since some disagreements about fundamental principles can be resolved in this way, it would surely be true that some deep disagreements are susceptible to rational resolution. (RR1) apparently does not capture Fogelin's idea.

There are a variety of roughly equivalent ways to improve upon the account of the availability of rational resolutions. What seems clear is that there is an evaluative component missing from (RR1). The idea is that a disagreement has a rational resolution available when there are some arguments and evidence that could be adduced that should lead to resolution. That is, there are some arguments that could be put forward to which the rational response is agreement. It may be that this obtains even in cases in which that would not be the actual response. And, there are cases in which there are no such arguments, yet people will reach agreement anyway. The following account better captures the intended idea:

RR2. There is a rational resolution of a disagreement available when there is some way of presenting arguments and evidence to which the rational response is a resolution of the disagreement (i.e., there is some way of presenting arguments and evidence that should lead to a resolution).

\section{Resolution of Disagreements}

I have said something about what it is for there to be a rational resolution of a disagreement available, but I have not as yet said anything definite about what counts as a resolution of a disagreement. I think that there is an important aspect of this that is easy to overlook.

There is a resolution of a disagreement if two people begin by disagreeing about something and then one person comes around to the other's point of view. Where there was disagreement, there ends up being agreement. And when this happens as a result of the presentation of arguments and evidence properly evaluated, then there has been a rational resolution of the disagreement. And if this is what should happen, even if it does not, there is a rational resolution available. Though this is true, I think that it ignores another way in which disagreements can be resolved.

The other possibility is briefly mentioned, but not developed, in Andrew Lugg's (1986) valuable critical commentary of Fogelin's essay. If two people disagree, where one believes $P$ and the other believes $\sim P$, one possible outcome of their discussion of the topic is that they both suspend judgment about $P(p .48)$. I believe that this also counts as a resolution of their disagreement. Thus, the disagreement can be resolved 
in three ways: both can end up believing $P$, both can end up believing $\sim \mathrm{P}$, or both can end up suspending judgment on the topic. (If we countenance degrees of belief, then they can resolve their disagreement by having the same degree of belief in P.) It may be that when the people suspend judgment they have not resolved the issue. That is, they have not come to an agreed upon conclusion about it. It is left open. But they have overcome their disagreement. Proposition $\mathrm{P}$ is no longer something about which they have different beliefs. The have resolved their disagreement. And, as I will argue next, this is often the rational resolution of a disagreement.

\section{Rationally Resolving Disagreements by Suspending Judgment ${ }^{1}$}

Suppose that two people disagree about some ordinary (non-framework) proposition. For example, suppose you and I disagree about who won baseball's World Series in 1955. We agree about the two teams that played, but we disagree about which of them won. In any normal circumstance, this disagreement can be rationally resolved. We can look it up. And if doubts about our first source are raised, we check additional sources. There is no apparent obstacle to rational resolution, even if one of us would in fact be intransigent and unyielding.

But suppose something odd and unexpected happens. Suppose that I say that I got my answer from some trusted baseball encyclopedia. We go to that trusted source and find that it supports my view. But you claim that you read a different account in another equally worthy source. We check that one out and, sure enough, it confirms your belief. At that point, the reasonable thing for both of us is to suspend judgment about which of the two teams won the 1955 World Series. Until we can find some basis to reject one of these sources as mistaken on this topic, we have no reason to prefer what one of them says to what the other says. The fact that my original belief was based on my original source is of no evidential or rational significance. I cannot sensibly stick to my original belief on the grounds that my encyclopedia supports my belief. The order in which we encountered the sources makes no difference. We both now have sources with conflicting information. We should both suspend judgment until we learn more.

Two further comments about this mundane example will matter for the argument to come. First, whatever emotional or financial or other practical investment we have in the matter makes no difference at all to this epistemic assessment. It may be that I care a lot about who won that year. Perhaps I have a bet riding on it. Perhaps some sense of personal worth depends on the truth about this issue. Perhaps it would be good for my health to retain my long-held belief. These practical matters have no epistemic punch. From an epistemic point of view, I should suspend judgment. Whatever non-epistemic merit continued belief may have, it is not epistemically justified.

Second, it is possible that there is no source available that will resolve the dispute. It is hard to make this seem plausible in the case of a disagreement about the outcome of the 1955 World Series. However, if the dispute concerned some event from the distant past, it is possible that there just is no information still available to settle the 
matter. Suspending judgment may be the right result in the long run as well as in the short run.

Here is the key idea to extract from consideration of this simple example. In this disagreement, and any normal one like it, there is always a rational resolution available. Either rational methods reveal the correct answer and we should agree about it, or suspension of judgment is the proper resolution. Notice also that something similar is true at each stage in the investigation. Suppose that further investigation would show that my original belief was mistaken. That does not tell us what we should believe before we undertake that investigation. Given that prior to looking it up we had no basis for thinking that my source was the mistaken one, we should both have suspended judgment until we learned that, and then both accepted your original view once we found out about this. And if we know that we will not be able to look it up, then we should suspend judgment as well. Of course, if there is some reason to think initially that one of our sources is more trustworthy, then we should both believe what that source reports. No matter what the situation, there is a rational resolution available, though that resolution may be suspension of judgment.

\section{Deep Disagreements and Suspending Judgment}

What remains to be considered is whether disagreements turning on framework propositions-deep disagreements-differ in any significant way from disagreements such as the mundane disagreement just described. As noted in Section I, Fogelin does give an argument for his central thesis, that deep disagreements cannot be rationally resolved. The premises of that argument include the claims that deep disagreements depend upon differences over "forms of life," and that such differences are not amenable to rational resolution. These premises are defended through discussion of examples, such as those about abortion and affirmative action. In the remainder of this section I will argue that deep disagreements are rationally resolvable, often using Fogelin's example about affirmative action to illustrate my points.

Fogelin says that the disagreement over affirmative action depends upon an underlying difference concerning whether groups as well as individuals have moral standing. Apparently, he thinks that the proposition that groups have moral standing is a framework proposition. Suppose, then, that after extensive discussion two people remain in disagreement concerning the merits of affirmative action. And suppose that they come to see that their attitude toward the proposition that groups have moral standing is the key underlying point of contention. As Lugg (1986) notes, they surely can reason about this proposition (p. 48). They can identify and assess the consequences of the proposition, they can examine the merits of similar propositions, they can assess apparent objections. There is no doubt that people do this frequently. However, as we all know, there is a good chance that a good faith effort on their part will not yield agreement.

Of course, the mere fact that the two people do not reach agreement fails to show that no rational resolution is available. It may be that one of them is making a mistake. 
Perhaps it is not exactly pig-headedness or intransigence that is getting in the way. Perhaps there is a failure to see the merits of the evidence. In that case, there is a rational resolution available. The failure is not in the methods, but in the one who is not dealing with the evidence properly. Another possibility is that the information they have provides no basis for accepting or rejecting the proposition that groups have moral standing. In that case, they should both suspend judgment. Thus, they can resolve the disagreement without resolving the issue. In these respects, the disagreement about a proposition such as "Groups have moral standing" hardly seems to differ from the disagreement about the 1955 World Series.

No doubt framework propositions are difficult to argue about. Passions about them may be strong, practical matters may tend to override evidential considerations, and disagreements about them may in fact tend not to be readily resolved. It may be that there is widespread unresolved disagreement about them. None of this shows that there is no rational resolution available. It may also be that framework propositions are in some way especially important. Perhaps they have important connections to many other beliefs. But this, also, fails to show that disagreements about them cannot be rationally resolved, even if suspension of judgment is the proper (though difficult) resolution.

The case for thinking that rational argument cannot resolve a disagreement about a framework proposition apparently depends upon Fogelin's claim that framework propositions are not supported by other individual propositions but instead are in some way connected to systems of propositions, or to "paradigms, models and styles of acting and thinking." In the discussion that follows, I will use the word "evidence" very broadly, so that it applies to the sorts of factors to which Fogelin refers. I must admit, however, that I am not clear about just what he means. I do not know what "styles of acting and thinking" he has in mind or how they are connected to the proposition that groups have moral standing.

Whatever these broadly evidential factors are, I do not see why they make framework propositions not amenable to rational inquiry. Whatever those factors may be, and whatever complex connections there may be between them and framework propositions, it still makes clear sense to raise a question about the rational status of the attitudes people take toward a framework proposition, such as the proposition that groups have moral standing. There are a limited number of possible answers to the question. Either one's overall evidence supports the proposition, or it goes against the proposition, or it is neutral. If this is right, then framework propositions have a rational status for individuals. Belief, disbelief, and suspension of judgment are the epistemically appropriate responses. In that case, however, people who disagree about a framework proposition can compare their evidence and, if they are rational, come to an agreement about it. As a result, there is a rational resolution of their disagreement available. Of course, it may be that suspension of judgement is the proper resolution, and thus, though there is a rational resolution of their disagreement, there may be no resolution of the issue. 
No doubt, Fogelin would disagree with the view just sketched. Presumably, he would argue that there is something special about framework propositions that prevents resolution in the familiar way described. In the remainder of this section I will briefly address three ways in which Fogelin's position might be defended. I do not mean to attribute any of these views to him. The first contends that since the participants in a disagreement may have different evidence, they can reasonably come to different conclusions and thus fail to reach agreement. The second contends that people can reasonably respond differently to the same evidence, and thus even after exploring all the arguments, they can reasonably fail to reach agreement. And the third contends that the rational status of framework propositions does not depend upon evidence or arguments, and thus people can reasonably fail to agree about them.

Consider first, then, the response according to which after discussion of the issue both sides might both reasonably maintain their respective views because one or both of them fail to convey to the other some relevant bit of evidence (broadly conceived). The idea is that this difference in evidence can make both people reasonable in their (incompatible) beliefs. Perhaps that can happen. Perhaps it does happen in actual disagreements. But to reach the conclusion that rational resolutions of disagreements are not even available in these cases, what must be added is not only that they do not convey this important evidence, but that they cannot convey it. It is difficult to imagine what this necessarily private evidence might be. And notice that if they have such evidence, they can report the fact that they have that evidence. And this has much the same evidential force for the recipient. Thus, even if there is unshared evidence in these disagreements, this does not help to show that the disagreements are not resolvable.

A second response relies on the idea that there can be multiple "legitimate" ways to respond to a body of evidence and thus diverse rational responses to that evidence. This response involves denying what I call "The Uniqueness Thesis" in Feldman (forthcoming (a)). That thesis says that there is only one reasonable response to a body of evidence. Perhaps the thought behind this view is that it is differing attitudes toward framework propositions that play a role in legitimizing these different responses to the same evidence. Thus, one might think about evidential relations in the following way: for those who accept the framework proposition "Groups have moral standing," the fact that a particular group has been harmed does provide evidence for a conclusion about giving that group preferential treatment. However, for those who reject that framework proposition that same evidence fails to support that conclusion. Evidential relations are partially determined by attitudes toward framework propositions.

Although I think that this view about evidential relations is a mistake, I will not contest it here. It is unclear how the view supports the idea that the disagreement cannot be rationally resolved. For one thing, people can discuss their different views about what supports what. The discussion about whether "Groups have moral standing" is true would, under the present view, simply be transformed into a discussion about whether evidence of past mistreatment of a group is evidence for the legitimacy of 
future corrective behavior. Surely issues about what supports what can be rationally discussed. And once such a discussion is undertaken, the same thing happens as happens in the original discussion. Either they come to have a rational basis for thinking one of the positions about evidential support is correct, or that the other position is correct, or they have no basis for choosing between the two positions. Whatever the outcome, they should believe, or suspend judgment, accordingly. Once again, there is a rational resolution of the disagreement. ${ }^{2}$

Even if this is wrong, something closely resembling a rational resolution of the disagreement is still in sight. If multiple ways of dealing with the evidence can be reasonable, then people should be able to recognize that fact. They should think that both views are "ok." I cannot fully understand what this amounts to. But it is quite unclear what exactly one can rationally deny about another's view if one recognizes the other's view is a rational response to the evidence. This seems to be saying the situation is one in which either of two options is acceptable, and individuals are free to choose one. But it is hard to see what sort of disagreement one has with someone who takes the other acceptable option. It would be a mistake to reject that option as "wrong."

The third, and final, way of defending the idea that disagreements about framework propositions cannot be rationally resolved depends upon the idea that framework propositions are somehow beyond rational assessment. Perhaps the idea is that rationality consists in properly drawing out the consequences of one's framework propositions in the light of the contingent evidence one obtains. Given that we can reason about the framework propositions Fogelin mentions, it is difficult to see why they are in this way beyond reason. That is, people do change their minds about propositions such as "Groups have moral standing" on the basis of arguments. If such propositions are beyond rational assessment, then such changes must be non-rational changes. It is difficult to identify a reason for thinking that that is true.

Furthermore, even if framework propositions are beyond rational assessment, suspension of judgment remains a possibility. Suppose one can see that there are alternative framework propositions and that they yield different beliefs in certain cases. If any attitude toward those framework propositions is equally legitimate, then one should not believe that one's own attitude is correct. One should see that there are alternative equally acceptable ways of organizing things. But then one is not justified in thinking that one's preferred way is correct. Suspension of judgment seems to be the required rational response.

I conclude that the reasons considered here for thinking that deep disagreements cannot be rationally resolved are not strong. Framework propositions, like other propositions, can be discussed and debated. They should be accepted or rejected, depending upon the evidence uncovered about them. And if the evidence is neutral, then suspension of judgment is the rational proper response. And this counts as a resolution of a disagreement. 


\section{Implications for Critical Thinking}

The methods of critical thinking are difficult to apply in some cases, including the cases to which Fogelin calls attention. It is surely true that teaching critical thinking to people will not smoothly lead to resolution of their disagreements in all cases, and, unfortunately, not in cases in which there would be great social benefits from achieving resolution. It may be true that some students have been misled into thinking that relatively simple applications of critical thinking methods will enable them to resolve complex moral and social issues. It may also be true that the benefits of critical thinking have been oversold by some. Nevertheless, if my arguments in this paper are sound, then Fogelin is mistaken in his contention that the techniques of critical thinking are not suitable for some disputes.

The line of thought presented here may seem to have its own troubling implications for critical thinking. If suspending judgment is the right attitude to take toward many of the hard cases, then one might reach the conclusion that the whole effort is pointless. If students get the idea that the upshot of thinking about all the arguments about affirmative action, abortion, and other controversial issues will be that they should suspend judgment about these issues, then possibly they will think that there is no reason to think about the arguments in the first place. This would not be a welcome outcome. Furthermore, one may think that there is something seriously wrong with a method that counsels suspension of judgment about such crucial issues.

Of course, I say only that suspension of judgment is the right attitude in some cases, but surely not all cases. I think that many disagreements can be rationally resolved and suspending judgment is not the proper outcome. And that leads to a reason to think things through - to try to figure out which sort of case any particular disagreement is. And even where suspension of judgment is the proper result, this is neither an awful outcome nor something that should make the process seem pointless. If one has a belief about an issue, and further investigation rationally leads to the result that one ought to suspend judgment about that issue, then the investigation has made a kind of progress. One will have learned that one's earlier view depended upon a deeper principle that, on reflection, is not well supported. And if that is in fact correct, it is difficult to see what is bad about finding it out.

Finally, at least as I see things, suspension of judgment really is the rationally proper attitude with respect to many controversial issues. To some degree, that is why they are controversial. It may be true that people have to act and governments have to adopt policies, and thus it is important that one take a stand on the issues of the day. However, it is also true that, whatever one's inclinations, it is often true that no rational resolution of the issue is available. Suspension of judgment is in fact called for. We need not hide this fact from our students. It is a truth revealed by critical thinking. 


\section{Notes}

${ }^{1}$ The line of thought developed in this section and the next draws heavily on arguments I have presented in Feldman, forthcoming (a).

${ }^{2}$ This claim relies upon an assumption not made explicit in the body of the text. It is that if you reasonably suspend judgment about whether your evidence supports $P$, then it is reasonable for you to suspend judgment about $\mathrm{P}$. I discuss principles such as this in Feldman, forthcoming (b).

\section{References}

Feldman, Richard. Forthcoming (a). "Epistemological Puzzles About Disagreement." In S. Hetherington (ed.), Epistemology Futures. Oxford: Oxford University Press.

Feldman, Richard. Forthcoming (b). "Respecting the Evidence," Philosophical Perspectives 19.

Fogelin, Robert. 1985. "The Logic of Deep Disagreements," Informal Logic 7, pp. 1-8. Lugg, Andrew. 1986. "Deep Disagreement and Informal Logic: No Cause for Alarm," Informal Logic 8, pp. 47-51.

Richard Feldman Department of Philosophy University of Rochester Box 270078 Rochester, NY 14627-0078 